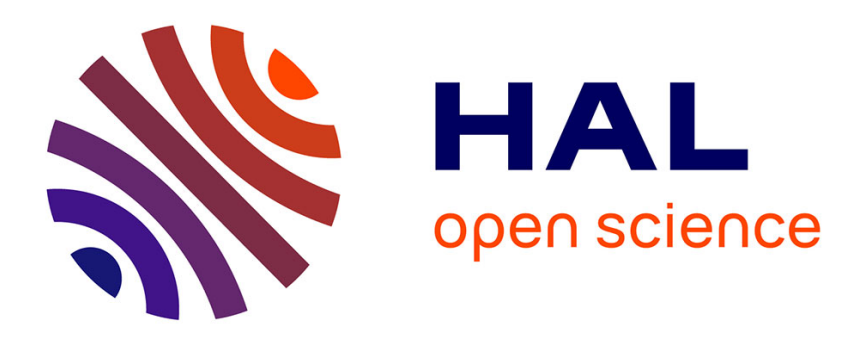

\title{
Entre droit et culture, l'exploitation sexuelle en procès
}

Mathilde Darley

\section{To cite this version:}

Mathilde Darley. Entre droit et culture, l'exploitation sexuelle en procès. Cultures \& conflits, 2021, Sexe, droit et migrations. La traite des êtres humains saisie par les institutions, 2 (122), pp.95-122. halshs-03293927

\section{HAL Id: halshs-03293927 https://shs.hal.science/halshs-03293927}

Submitted on 21 Jul 2021

HAL is a multi-disciplinary open access archive for the deposit and dissemination of scientific research documents, whether they are published or not. The documents may come from teaching and research institutions in France or abroad, or from public or private research centers.
L'archive ouverte pluridisciplinaire HAL, est destinée au dépôt et à la diffusion de documents scientifiques de niveau recherche, publiés ou non, émanant des établissements d'enseignement et de recherche français ou étrangers, des laboratoires publics ou privés. 


\section{Entre droit et culture, l'exploitation sexuelle en procès}

\section{Mathilde DARLEY}

Mathilde Darley est chargée de recherche CNRS au Cesdip (Centre de recherches sociologiques sur le droit et les institutions pénales), directrice adjointe du Cesdip et chercheuse associée au Centre Marc Bloch (Berlin). Ses thèmes de recherche incluent le contrôle de l'immigration, l'enfermement des étrangers, la prostitution et la traite des êtres humains, la sociologie de la police et la justice pénale. Elle a coordonné entre 2014 et 2018 le projet franco-allemand ProsCrim (ANR-DFG) portant sur la traite des êtres humains et le proxénétisme. Contact : mathilde.darley@,gmail.com

"Oui, la prostitution chinoise, alors c'est pas très politiquement correct de dire ça mais pour moi elle est... elle est plus propre, entre guillemets, c'est-à-dire que les conditions dans lesquelles les Chinoises exercent la prostitution elles sont vraiment meilleures [...] y a pas de violences, elles se font pas frapper, y a pas... [...] elles sont vraiment leur propre proxénète! [...] on est loin loin pour moi de la prostitution roumaine, où pour le coup les filles travaillent dans des conditions insalubres réelles, elles sont victimes de violences quotidiennes mais qui tiennent moins, je pense, c'est mon avis hein, aux réseaux de proxénètes qu'à la vie dans ces communautés-là, qui est de toute manière ultra-violente, qui est de toute manière très insalubre ${ }^{l} . "$

Révélant la prégnance de classifications reposant sur l'origine prêtée aux justiciables comme aux victimes, le discours de cette avocate associe à l'origine, réelle ou supposée, des justiciables des modalités de commission de l'infraction présentées comme «culturelles », venant justifier des hiérarchisations d'ordre moral. Cette grille de lecture, que

\footnotetext{
${ }^{1}$ Entretien, Kathy Lemercier, Avocate de la défense, 21/04/2016, par Mathilde Darley et Muriel Mille. Les noms des personnes rencontrées en entretien et en audience ont été anonymisés, de même que les procès observés (dont les dossiers sont généralement désignés par les professionnels du droit sous le nom du ou de la prévenu principal).
} 
l'on retrouve dans les propos de nombre de professionnels du droit ${ }^{2}$ ayant eu à connaître des affaires de proxénétisme aggravé et/ou de traite des êtres humains à des fins d'exploitation sexuelle, s'inscrit de fait dans un contexte politique et organisationnel propice à son émergence et à sa stabilisation. En effet, les termes dans lesquels la traite des êtres humains est réapparue sur les agendas internationaux et nationaux au début des années 1990 ont généralement conduit non seulement à mettre l'accent sur la dimension sexuelle de l'exploitation ${ }^{3}$ mais aussi, et surtout, à consolider l'amalgame entre traite et migration. En France, le traitement des contentieux de proxénétisme aggravé et traite des êtres humains par des juridictions spécialisées dans le crime organisé est venu conforter cette association entre les formes les plus graves d'exploitation sexuelle et l'origine étrangère des justiciables : il place en effet au cour du travail judiciaire les dossiers présentant des ramifications internationales, plus susceptibles d'impliquer des étrangers. Enfin, le contexte abolitionniste français, dans lequel la prostitution n'est certes pas illégale mais ne constitue néanmoins pas une activité professionnelle reconnue, concentre par ailleurs les activités de contrôle du sexe tarifé sur ses formes les plus visibles et " saisissables ", c'est-à-dire celles se déployant dans la rue et impliquant majoritairement des étrangères ${ }^{4}$ : ces dernières se trouvent alors logiquement surreprésentées en bout de chaîne pénale, devant les tribunaux.

Ainsi, les professionnels du droit (avocats de la défense et de la partie civile, magistrats du siège et du parquet) interrogés dans le cadre du projet de recherche ProsCrim (voir encadré) associent d'emblée l'infraction de traite des êtres humains à des fins d'exploitation sexuelle

\footnotetext{
${ }^{2}$ La revue Cultures et Conflits travaille actuellement à l'élaboration de recommandations relatives à l'écriture inclusive. En l'état actuel, les formes privilégiées sont celles qui permettent de visibiliser la présence des femmes sans utilisation du point médian. Néanmoins, dans cet article, certains génériques masculins ont été conservés pour désigner aussi bien des femmes que des hommes lorsque le remplacement par une formule épicène compromettait la précision du propos. ${ }^{3}$ Alors que les formes d'infractions associées à la traite des êtres humains incluent également le travail ou les services forcés, le prélèvement d'organes, l'incitation à commettre des délits, la réduction en esclavage ou servitude, l'exploitation de la mendicité, ou encore les conditions de travail ou d'hébergement indignes (Voir l'article Art. 225-4-1. - I. du Code pénal français, 5/08/2013).

${ }^{4}$ Les interlocuteurs policiers rencontrés estiment à $90 \%$ « au moins » la part des « personnes de nationalité étrangère » dans la prostitution de rue parisienne (Entretien conduit avec le chef de la brigade de répression du proxénétisme, Mathilde Darley et Gilles Favarel-Garrigues, 28/10/2015). Voir aussi Mathieu L., La fin du tapin. Sociologie de la croisade pour l'abolition de la prostitution, Editions François Bourin, Paris, 2013, p. 250.
} 
à l'acheminement de personnes (généralement des femmes) depuis l'étranger vers la France, dans le but de tirer profit de leur prostitution - alors même que la définition nationale et internationale de la traite ne conditionne pas sa qualification au franchissement d'une frontière ${ }^{5}$. À l'instar de l'avocate citée en exergue, ils et elles déclinent par ailleurs couramment les formes d'exploitation sexuelle rencontrées en fonction de l'origine, réelle ou supposée, des individus impliqués et des « cultures » qui lui sont associées ${ }^{6}$. Ainsi, le proxénétisme « rom» ou « roumain $^{7}$ » est généralement décrit par les professionnels du droit comme « sordide et glauque ${ }^{8}$ » : son fonctionnement « clanique » et « conjugal $\cdot »$ découlerait de son caractère «culturellement admis » et conduirait à l'exploitation de la prostitution des femmes par leurs époux oisifs, ainsi qu'à des degrés de violence inégalés de ces derniers à l'encontre des premières. Le proxénétisme chinois est au contraire présenté comme "plus propre », en raison de son fonctionnement « entrepreneurial » et de son organisation « horizontale » marquée par la « solidarité » entre personnes consentantes, « travailleuses » et « sans histoires ». Le proxénétisme nigérian, enfin, se distinguerait quant à lui par l'emprise inédite exercées par les proxénètes, souvent de sexe féminin, sur les victimes. Cette emprise résulterait notamment du recours au juju (vaudou'), dont l'exotisme est mis en exergue, et qui vise à garantir le remboursement des dettes exorbitantes contractées par

\footnotetext{
${ }^{5}$ Voir par exemple la définition prévue à l'article 3 du Protocole additionnel à la Convention des Nations-unies de lutte contre la criminalité transnationale organisée (2000), celle de la Convention du Conseil de l'Europe sur la lutte contre la traite des êtres humains (2005), la directive 2011/36/U6 du Parlement et du Conseil européens (2011) et l'article Art. 225-4-1. - I. du Code pénal français (2013).

${ }^{6}$ À ces classifications s'ajoutent plus occasionnellement celles du «proxénétisme de cité » et des " escorts de l'Est».

${ }^{7}$ Cette classification interne à la profession judiciaire semble poser comme une équivalence la nationalité roumaine, l'engagement dans une activité prostitutionnelle, et l'appartenance à la " communauté rom », et apparaît donc largement problématique.

${ }^{8}$ Les propos entre guillemets dans ces lignes sont tirés d'entretiens avec des professionnels du droit et/ou d'observations d'audiences au tribunal.

${ }^{9} \mathrm{Ce}$ terme, qui renvoie à un contenu assez flou, est généralement utilisé par les femmes nigérianes (mais aussi par les acteurs judiciaires) pour évoquer à la fois leurs croyances et les rites subis au cours d'un serment d'allégeance par lequel elles se sont engagées à rembourser une dette (au montant généralement exorbitant) à la personne ayant organisé leur voyage vers l'Europe, et à ne pas dénoncer leur proxénète à la police. Voir IFRA Nigeria/ECPAT France, Groupes religieux, sociaux et criminels dans la traite des filles et des femmes nigérianes, 2019, disponible sur https://ecpat-france.fr/www.ecpat-france/wp-

content/uploads/2019/04/WEB rapport nigeria FR.pdf ; Taliani S., « Coercion, Fetisches and Suffering in the Daily Lives of Young Nigerian Women in Italy », Africa, vol. 82, 2012, pp. 579608 .
} 
les victimes à l'égard des « Madam » organisant leur recrutement et leur exploitation.

Certes, des catégorisations de même nature, revenant à assigner des traits immuables aux personnes censées composer des groupes fondés sur l'origine et pensés comme homogènes ${ }^{10}$, sont observées dans d'autres milieux professionnels ${ }^{11}$. Elles y semblent cependant généralement « clandestines ${ }^{12}$ », cantonnées à $l^{\prime}$ « informel $»^{13}$, quand elles se font au contraire ici récurrentes ${ }^{14}$ : au cours des entretiens, elles sont tour à tour invoquées par les différentes parties au procès pour critiquer la méconnaissance par l'institution judiciaire des particularismes culturels ou au contraire relativiser leur poids dans l'explication des phénomènes délinquants visés, attester de la " différence culturelle » entre les magistrats et les justiciables ou en minimiser la portée, mais aussi, plus généralement, pour justifier le trouble persistant dans l'administration de la preuve en matière de traite et de proxénétisme ${ }^{15}$, comme l'énonce un avocat de la défense : «Pourquoi on comprend rien ? Ben parce que c'est très très très complexe, et qu'il y a des enjeux qui nous appartiennent pas : il y a un problème culturel qui fait qu'on comprend pas ${ }^{16}$. »

Il s'agira donc d'explorer ici l'hypothèse selon laquelle l'indétermination du droit entourant la prostitution et le proxénétisme

\footnotetext{
${ }^{10}$ Terrio S. J., Judging Mohammed. Juvenile Delinquency, Immigration, and Exclusion at the Paris Palace of Justice, Stanford, Stanford University Press, 2009.

${ }^{11}$ Sur leur prégnance dans le milieu médical, voir Prud'Homme D., «Du « soin global » au traitement discriminatoire. La prise en charge de patientes identifiées comme roms dans un service de gynéco-obstétrique parisien ", Terrains \& travaux, vol. 2, n²9, 2016, pp. 85-104 ; Nacu A., "A quoi sert le multiculturalisme ? Pratiques médicales et catégorisations des femmes "migrantes" dans trois maternités franciliennes ", Sociologie du travail, n53, 2011, pp. 109-130 ; dans le travail policier, voir Gauthier J., « Origines contrôlées. Police et minorités en France et en Allemagne », Sociétés contemporaines, vol. 1, n97, 2015, pp. 101-127.

${ }^{12}$ Gauthier J., Origines contrôlées : la police à l'épreuve de la question minoritaire à Paris et à Berlin, Thèse de sociologie, UVSQ, 2012.

${ }^{13}$ Nacu A., op. cit., p. 112.

14 Notons toutefois que Nicolas Jounin relève lui aussi l'usage explicite des catégories d'appartenance ethnico-raciale comme critère d'ordonnancement des travailleurs du bâtiment par leurs employeurs : Jounin N., "L'ethnicisation en chantiers. Reconstructions des statuts par l'ethnique en milieu de travail », Revue européenne des migrations internationales [En ligne], vol. 20, n³, 2004, http://journals.openedition.org/remi/2025. Consulté le

${ }^{15}$ Sur la difficulté des professionnels du droit à se repérer face à l'infraction de traite ou proxénétisme, voir aussi G. Favarel-Garrigues et L. Mathieu, dans ce numéro.

${ }^{16}$ Entretien, Roméo Elfons, Avocat de la défense, 1/02/2017, par Mathilde Darley.
} 
en France, déjà soulignée ailleurs ${ }^{17}$, encourage le recours, chez les professionnels du droit, au cadrage culturaliste de l'infraction comme référentiel extra-juridique orientant la construction du jugement pénal ${ }^{18}$.

Différents travaux ont mis en lumière déjà, dès le début des années 2000, l'incidence des stéréotypes, de race et de genre notamment, sur la définition des politiques de lutte contre la traite et leur traitement politique et médiatique ${ }^{19}$. Les travaux portant spécifiquement sur les effets produits par ces assignations sont cependant restés rares. En particulier, leurs éventuelles traductions en termes d'opérationnalisation du droit et de tracé des frontières juridiques demeurent notoirement sous-explorées. En dépit du paradoxe fréquemment soulevé entre l'ampleur supposée de la traite à des fins d'exploitation sexuelle et le nombre restreint de procès y afférant ${ }^{20}$, l'arène du tribunal constitue sans doute la face la plus cachée des politiques de lutte contre la traite, alors même qu'elle constitue l'espace ultime de labellisation des comportements, l'« arène morale ${ }^{21} »$ où le

\footnotetext{
${ }^{17}$ Mathieu L., op.cit., 2013, p. 54 ; Mainsant G., « Gérer les contradictions du droit "par le bas" ». Logiques de police en concurrence dans le contrôle de la prostitution de rue à Paris », Actes de la recherche en sciences sociales, vol. 3, n¹98, 2013, pp. 23-34. Ici, la nature du délit visé, c'est-àdire l'exploitation de la sexualité d'autrui sous une forme prostitutionnelle, place en outre l'institution pénale dans une position de double inconfort juridique et moral résultant notamment de l'ambiguïté du droit français : tout en s'inscrivant dans une perspective abolitionniste assimilant toute forme de prostitution à une violence faite aux femmes, la loi ne réprime pas (plus) la vente de services sexuels, mais condamne cependant le fait pour les tiers d'en tirer profit et, depuis 2016, d'y recourir (en tant que client).

${ }_{18}$ Valverde M., " Pragmatist and Non-Pragmatists Knowledge Practices in American Law », PoLAR, vol. 26, n², 2003, pp. 86-108.

${ }^{19}$ Voir par exemple Berman J., «(Un)Popular Strangers and Crises (Un)Bounded: Discourses of Sex-Trafficking, the European Political Community and the Panicked State of the Modern State », European Journal of International Relations, vol. 9, $\mathrm{n}^{\circ}$ 1, 2003, pp. 37- 86 ; Andrijasevic R., « La traite des femmes d'Europe de l'Est en Italie », Revue européenne des migrations internationales, vol. $21, \mathrm{n}^{\circ} 1,2005$, pp. 155- 175. Andrijasevic R., « Beautiful dead bodies: Gender, migration and representation in anti- trafficking campaigns ", Feminist Review, nº6, 2007, pp. 24- 44 ; de Montvalon P., « Les rapports de classe et de race. Les angles morts du traitement politique et institutionnel de la prostitution en France », Hommes \& migrations, n¹311, 2015, pp. 105-112.

${ }^{20}$ Jakšić M., La traite des êtres humains en France : de la victime idéale à la victime coupable, Paris, CNRS Editions, 2016 ; Pates R., Schmidt D., Die Verwaltung der Prostitution. Eine vergleichende Studie am Beispiel deutscher, polnischer und tschechischer Kommunen, transcript Verlag, Bielefeld, 2009.

${ }^{21}$ Komter M. L., " Remorse, Redress, and Reform: Blame-taking in the courtroom », in Travers M., Manzo J.F. (ed.), Law in action : Ethnomethodological and conversation analytic approaches to law, Ashgate, Dartmouth Publishing Co, 1997, pp. 239-264.
} 
bien et le mal se trouvent (re)produits et « l'ordre moral dominant confirmé ${ }^{22} »$.

À partir d'un corpus ethnographique inédit alliant entretiens avec des professionnels du droit et observations d'audiences en chambre correctionnelle, je chercherai donc à montrer que les opérations de catégorisation des justiciables dans des groupes sociaux définis par l'origine supposée de leurs membres et les attributs culturels qui lui sont associés répondent à des logiques allant au-delà de la seule visée « descriptive ${ }^{23}$ » des populations et des comportements impliqués. Plus spécifiquement, je développerai l'hypothèse qu'elles sont professionnellement signifiantes dans l'arène judiciaire, bien que leur rôle varie en fonction des professionnels qui s'en saisissent, et que leur portée ne s'appréhende qu'à la lumière des autres formes d'assignations dont elles permettent le déploiement : sous couvert de différences culturelles, se trouve en effet ici activées des assignations racialisantes ${ }^{24}$ soulignant l'inadéquation des justiciables à un ordre national sexué et sexuel $^{25}$, que l'énoncé de la peine doit permettre de réaffirmer et de rétablir.

Ce texte s'inscrit dans le cadre du projet franco-allemand ProsCrim (La traite des êtres humains saisie par les institutions) co-financé par l'ANR
(ANR-13-FRAL-0014-01)
et
la
DFG
(Deutsche

Forschungsgemeinschaft) entre 2014 et 2018. L'équipe française, coordonnée par Mathilde Darley, impliquait également Gilles FavarelGarrigues, Alban Jacquemart, Milena Jaksic, Nadège Ragaru, Gwénaëlle Mainsant, Lilian Mathieu et Muriel Mille. L'enquête conduite collectivement s'intéressait aux opérations de labellisation des victimes et auteurs étrangers d'exploitation sexuelle (traite des êtres humains et/ou proxénétisme), en portant une attention particulière aux

\footnotetext{
${ }^{22}$ Vanhamme F., Beyens K., «La recherche en sentencing : un survol contextualisé », Déviance et Société, vol. 31, n², 2007, p. 199-228.

${ }^{23}$ Keyhani N., Laurens S., «Introduction. La production officielle des différences culturelles », Cultures \& Conflits, nº107, 2017, pp. 9-13.

${ }^{24} \mathrm{~L}$ 'expression d'assignation racialisante ou de racialisation permet d'insister sur la dimension processuelle de l'essentialisation d'une origine (réelle ou supposée) et de radicalisation de son altérité débouchant sur sa minorisation. Voir Mazouz S., Race, Paris, Anamosa, 2020, p. 50.

${ }^{25}$ Darley M., «Le proxénétisme en procès : la réaffirmation d'un ordre sexuel national ? », in G.

Girard, I. Perreault, N. Sallée (dir.), Sexualité, savoirs et pouvoirs, Montréal, Presses Universitaires de Montréal, 2019, pp. 155-165.
} 
pratiques policières et judiciaires. Les matériaux d'enquête collectés dans le cadre de ce projet de recherche sont ainsi constitués d'entretiens et d'observations auprès de différents acteurs impliqués dans les politiques publiques de lutte contre la traite : la police (services spécialisés et non spécialisés), la justice, mais aussi les associations d'aide aux personnes en situation de prostitution et les arènes « partenariales » de l'action publique, marquées par la rencontre entre acteurs du social et du pénal ${ }^{26}$.

Ce texte porte plus spécifiquement sur le rôle de l'origine et de la « culture » prêtées aux prévenus et aux victimes dans le traitement pénal du proxénétisme et de la traite des êtres humains. Pour ce faire, il s'appuie sur l'observation de trente-cinq procès pour proxénétisme aggravé et/ou traite des êtres humains devant les chambres correctionnelles des tribunaux de différentes grandes villes françaises. Ces observations ont été pour la plupart réalisées en binômes afin de faciliter la prise de notes, laquelle incluait non seulement un verbatim des propos tenus par les différents protagonistes au cours de l'audience, mais aussi la consignation d'observations relatives aux réactions et attitudes marquant l'étonnement, l'agacement, la connivence, etc. chez les professionnels du droit, les justiciables et/ou les victimes, mais aussi dans le public. Les procès suivis s'étalaient sur des durées allant d'un à treize jours, aboutissant à un total de cent treize jours d'audience observés, pour une durée cumulée estimée à neuf cents heures d'observation environ ${ }^{27}$.

Pour constituer ce corpus d'observations, nous avons cherché, par des appels réguliers au greffe du tribunal, à suivre l'agenda des chambres spécialisées sur le crime organisé, qui traitent la plupart des dossiers de traite et de proxénétisme aggravé. Pourtant, l'information ainsi obtenue s'est révélée parcellaire : outre qu'elle reste soumise au bon vouloir des greffiers, ces derniers ne voient dans l'agenda des semaines à venir que les noms des prévenus, et déduisent donc généralement de leur patronyme leur éventuelle implication dans un dossier d'exploitation sexuelle dont ils communiquent le cas échéant (et après vérification dans le système de la nature de l'infraction) la date d'audience aux chercheurs. Si ce biais dans la sélection des informations empêche toute prétention à l'exhaustivité dans la constitution du corpus, il fournit

\footnotetext{
${ }^{26}$ Darley Mathilde, « Pouvoirs publics et associations en lutte contre la traite des êtres humains : légitimations croisées ", article à paraitre.

${ }^{27}$ Sur l'organisation concrète des audiences, voir G. Favarel-Garrigues et L. Mathieu, dans ce numéro.
} 
néanmoins une première piste d'analyse intéressante quant au lien établi, au sein de l'institution judiciaire, entre origine supposée et implication dans la traite et/ou le proxénétisme.

Les observations d'audience ont par ailleurs été complétées par des entretiens réalisés avec différents professionnels du droit, dont vingtsept avocats de la défense, cinq avocats de la partie civile, huit juges du siège et onze procureurs. S'y ajoutent, quoique de manière moins centrale ici, les propos recueillis en entretiens auprès d'acteurs policiers, ainsi que de représentants des pouvoirs publics impliqués dans la politique pénale. Les observations et entretiens ont été réalisés par différents membres de l'équipe du projet ProsCrim puis mis en commun et débattus collectivement. Si le présent article n'engage que l'auteure, il doit évidemment beaucoup aux contributions des collègues ayant pris part à l'enquête ${ }^{28}$ ainsi qu'aux discussions collectives ayant ponctué la réalisation de l'enquête ProsCrim et dont témoigne l'ensemble de ce numéro ${ }^{29}$.

\section{Un traitement pénal différentiel ? L’impossible objectivation} statistique d'un biais fondé sur l'origine dans les procès pour traite

Dès la première moitié $\mathrm{du} \mathrm{XX}^{\mathrm{e}}$ siècle, des études nord-américaines portant sur la prise de décision des magistrats au pénal fournissent la preuve statistique de l'inégalité des traitements réservés par le système judiciaire aux populations minorisées, et en particulier aux Noirs et aux pauvres $^{30}$. Ces études en sentencing, s'attelant à la question des disparités dans les peines et en interrogeant les déterminants, connaissent un développement sans précédent au tournant des années 1960-1970, à l'apogée de l'État social et de sa logique intégrative ${ }^{31}$. Le droit est alors, de plus en plus, appréhendé comme une construction sociale à l'appui du groupe dominant ${ }^{32}$, et les études en sentencing sont

\footnotetext{
${ }^{28}$ Chaque extrait d'entretien ou de carnet de terrain convoqué ici mentionne le chercheur ou la chercheuse impliquée dans le recueil des données.

${ }^{29}$ Je remercie Jérémie Gauthier, Jacques de Maillard et Benoît Majerus pour leurs conseils avisés sur de premières versions de ce texte, ainsi que les évaluateurs et évaluatrices anonymes de la revue dont les commentaires ont fort utilement guidé la rédaction de la mouture finale.

${ }^{30}$ Sellin T., Conflits de culture et criminalité, Paris, Pedone, 1984 (1938).

${ }^{31}$ Wyvekens A., "La justice et la "diversité culturelle" : "les yeux grands fermés"? », Archives de politique criminelle, vol. 1, n⿳36, 2014, pp. 123- 146.

${ }^{32}$ Robert P., Faugeron C., Kellens G., « Les attitudes des juges à propos des prises de décision », Annales de la Faculté de droit de Liège, vol. 20, 1975.
} 
au fondement des premières dénonciations d'une justice à la fois de classe et racialisée ${ }^{33}$. S'inscrivant dans cette tradition scientifique, différents travaux récents ont ainsi montré que les étrangers faisaient l'objet de sanctions plus sévères ${ }^{34}$, tendance encore accentuée en cas de séjour irrégulier ${ }^{35}$ par un mécanisme où droit pénal et droit des étrangers ${ }^{36}$ semblent venir se renforcer mutuellement ${ }^{37}$.

Les procès observés pour traite à des fins d'exploitation sexuelle et/ou proxénétisme aggravé, et les entretiens réalisés à leur issue avec les professionnels du droit, rendent cependant délicate l'objectivation statistique du rôle de l'origine et de la culture prêtée aux protagonistes dans la construction du jugement. Il s'agit, d'abord, d'un contentieux limité : bien qu'en progression, les affaires de proxénétisme aggravé ou traite des êtres humains (TEH) traitées par les chambres correctionnelles spécialisées ne représentent qu'une partie des dossiers de criminalité organisée dont elles ont la charge. Ensuite, l'infraction de TEH à des fins d'exploitation sexuelle n'est pas isolée, dans la statistique pénale, mais regroupée avec d'autres infractions sous le « champ large » de la traite des êtres humains : le comptage cumulé d'infractions dont on suppose qu'elles peuvent être associées à la traite permet alors de fournir aux instances internationales des chiffres nettement plus élevés que ceux que produirait la quantification des seules affaires jugées sous la qualification juridique de traite des êtres

\footnotetext{
${ }^{33}$ Voir par exemple, en France, Herpin N., L'application de la loi: deux poids, deux mesures, FeniXX, 1977 ; Aubusson De Cavarlay, Bruno, «Hommes, peines et infractions : la légalité de l'inégalité ", L'Année sociologique, n³5, 1985, pp. 275-309 ; Gautron V., Retière J.-N., Des destinées judiciaires pénalement et socialement marquées, in Danet J. (dir.), La réponse pénale, Rennes, PUR, 2013, pp. 211-251.

${ }^{34}$ Jobard F., Névanen S., « La couleur du jugement », Revue française de sociologie, vol. 48, n², 2007, pp. 243-272.

${ }^{35}$ Léonard T., « Ces papiers qui font le jugement. Inégalités entre Français et étrangers en comparution immédiate », Champ pénal/Penal field, vol. 7, 2010.

${ }^{36}$ Simon C., Truffin B., «"« La diversité culturelle en procès : l'expérience de la justice belge par les familles à composante migratoire, quels enjeux pour le pluralisme juridique? », Anthropologie et sociétés, vol. $40, \mathrm{n}^{\circ} 2,2016$, pp. 107-129.

${ }^{37}$ La surreprésentation des étrangers dans la chaîne pénale est évidemment aussi à lire comme le résultat des pratiques discriminatoires de contrôle, en amont, par l'institution policière. Voir notamment Jobard F., Lévy R., Lamberth J., Nevanen S., « Mesurer les discriminations selon l'apparence : une observation standardisée des contrôles d'identité à Paris ", Population, vol. 3, n³7, 2012, pp. 423-452 ; Gauthier J., « Origines contrôlées. Police et minorités en France et en Allemagne », Sociétés contemporaines, vol. 1, n97, pp. 101-127; Slaouti O., Jobard F., « Police, justice, Etat : discriminations raciales », in Slaouti O. et al. (dir.), Racismes de France, Paris, La Découverte, 2020.
} 
humains, et plus encore de traite à des fins d'exploitation de la prostitution $^{38}$.

Peu d'éléments sont en outre disponibles, dans le cadre de notre étude, sur ces personnes prévenues et/ou condamnées pour traite à des fins d'exploitation sexuelle et/ou proxénétisme aggravé : d'abord, les dossiers d'instruction, parfois mis à disposition par les avocats, n'ont pu faire l'objet que d'un accès inégal, en l'absence d'accord obtenu de la présidence des tribunaux concernés quant à leur consultation systématique ; ensuite, leur caractère peu fourni (tout comme les débats à l'audience) eu égard aux « éléments de personnalité 》 et aux parcours de justiciables étrangers, souvent sans-papiers, complique la mise en perspective de leurs trajectoires personnelles, socioprofessionnelles et judiciaires avec leurs éventuelles condamnations.

Par ailleurs, notre matériau ethnographique se révèle également complexe à traiter quantitativement en raison des importants aléas dont il est porteur : malgré une politique pénale appelant à retenir plus systématiquement la qualification de traite, les procès pour traite et/ou proxénétisme aggravé, à la différence d'autres contentieux « de masse ", restent relativement marginaux et peu visibles dans l'économie générale de l'activité judiciaire. La difficulté à obtenir de l'institution judiciaire les dates d'audience et les infractions visées prive en outre le corpus mobilisé de toute prétention à l'exhaustivité ou à la " représentativité » (voir encadré) et les variations importantes que présente l'infraction dans ses manifestations (et leur degré de gravité)

\footnotetext{
${ }^{38}$ Cet arrangement statistique conduit ainsi le ministère de la Justice à avancer, pour l'année 2013 (année où est introduite en droit français une nouvelle définition de la traite des êtres humains article 225-4-1 du Code Pénal, harmonisant ainsi la législation nationale avec la directive européenne Directive 2011/36/UE du Parlement européen et du Conseil du 5 avril 2011 concernant la prévention de la traite des êtres humains et la lutte contre ce phénomène ainsi que la protection des victimes et remplaçant la décision-cadre 2002/629/JAI du Conseil), le chiffre de 1420 infractions relevant du « champ large » de la traite dont $127(9 \%)$ relatives à la TEH, $1154(81 \%)$ relatives au proxénétisme, $127(9 \%)$ relatives à la TEH, $107(8 \%)$ aux conditions de travail et d'hébergement indignes, $24(2 \%)$ au recours à la prostitution et $8(1 \%)$ à l'exploitation de la mendicité. Voir le rapport CNCDH, 2016, p. 106. A la demande de la Commission Nationale Consultative des Droits de l'Homme (CNCDH), les précisions statistiques apportées a posteriori permettent cependant d'estimer à 37 le nombre de condamnations pour traite à des fins d'exploitation sexuelle en 2013, et donc de souligner l'écart statistique entre les chiffres des « infractions pour TEH » avancés dans les rapports à destination d'institutions internationales évaluant la politique pénale de la France en la matière et les condamnations effectivement prononcées pour la seule traite à des fins d'exploitation de la prostitution. CNCDH, Rapport sur la lutte contre la traite et l'exploitation des êtres humains, 2016, pp. 106-107.
} 
comme dans les infractions connexes qui lui sont associées ${ }^{39}$ compliquent le fait d'isoler statistiquement ou d'objectiver quantitativement des formes de standardisation du jugement.

Enfin, vouloir saisir le rôle de l'origine (réelle ou supposée) des prévenus dans le déroulé de l'audience et le prononcé des peines fait évidemment courir au chercheur le risque d'un prisme déformant : si les professionnels du droit convoquent de manière récurrente la culture supposée des justiciables en entretiens mais aussi, quoique de manière parfois moins explicite, à l'audience, comment déterminer si « la frontière posée en paroles règle les pratiques ${ }^{40}$ », c'est-à-dire si le jugement finalement rendu se construit sur le référent culturel invoqué ? Face à l'indétermination du droit relatif à la prostitution et au proxénétisme et à l'inconfort des juges par rapport à l'infraction de traite plus récemment introduite, je chercherai à montrer, dans les développements qui suivent, en quoi les processus d'altérisation enchâssés dans le travail juridique de production d'une vérité à l'audience revêtent une fonction cognitive, pour les acteurs du droit, de caractérisation de l'infraction et de hiérarchisation de ses auteurs, mais aussi de ses victimes.

\section{La « culture » à l'audience : usages et controverses}

Les travaux en sentencing cités ci-dessus ont rapidement posé le constat que « ce que les juges disent faire ne correspond pas linéairement à ce qu'ils font effectivement ${ }^{41}$ ", soulignant ainsi l'importance d'une analyse intégrant, à travers l'observation, le processus de construction de sens « en train de se faire ${ }^{42}$ » au cours de l'audience. Répondant à cette invitation, ce texte propose d'analyser le rôle et la place, dans la dramaturgie du procès et son issue pénale, de la " grammaire de l'altérité culturelle ${ }^{43}$ » déployée, à propos des prévenus comme des victimes, par les professionnels du droit. Outre les propos recueillis en

\footnotetext{
${ }^{39}$ Voir aussi G. Favarel-Garrigues et L. Mathieu, dans ce numéro.

${ }^{40}$ Jounin N., op. cit.

${ }^{41}$ Vanhamme F., Beyens K., op. cit. ; Lenoir R., " Processus pénal et mise en détention provisoire ", Droit et société, vol. 30, n ${ }^{\circ} 1,1995$, pp. 357- 365.

${ }^{42}$ Faget J., "La fabrique de la décision pénale. Une dialectique des asservissements et des émancipations », Champ pénal/Penal field, vol. 5, 2008.

${ }^{43}$ Voir la "grammar of cultural otherness" dans D’hondt S., « Others on trial: The construction of cultural otherness in Belgian first instance criminal hearings », Journal of Pragmatics, vol. 41, 2009, pp. 806-828 (p. 807).
} 
entretiens, l'ethnographie de l'audience judiciaire, en tant qu'espace de confrontation entre les différents protagonistes, permet en effet non seulement d'avoir une " prise directe sur les multiples interactions qui produisent - et simultanément que produit - la pratique judiciaire au quotidien $^{44}$ ", mais aussi, et surtout, d'en questionner le caractère éventuellement performatif ${ }^{45}$. Il s'agira ainsi, en particulier, d'analyser la fonction cognitive de cette construction des justiciables comme « cultural other ${ }^{46}$ » pour les professionnels du droit qui s'en saisissent, en tenant compte de leur positionnement respectif dans l'arène du débat.

"Ici, c'est incroyable, mais au Nigéria c'est monnaie courante » : la culture comme argument de défense

À partir des années 1980, un courant de recherche se développe dans la littérature anglo-américaine autour de l'idée de "défense culturelle » (cultural defense $e^{47}$ ), qui cherche à appréhender le rôle de l'origine des prévenus et de la « culture » qui s'y trouve associée sur le déroulé de l'audience, et en particulier sur les arguments déployés pour leur défense. En France toutefois, la littérature académique et les acteurs du droit restent relativement silencieux quant à la place, à l'audience, des « différences culturelles » imputées au prévenu et censées renvoyer «à des normes, des valeurs, des pratiques différentes de celles de la culture majoritaire ${ }^{48} »$ : dans un système républicain pensé comme " colourblind $^{49} »$, ou « aveugle aux différences ${ }^{50} »$, les rares travaux abordant la question concluent généralement à la disqualification, par les professionnels du droit, de la «culture » comme élément éclairant les comportements, et donc à l'inefficacité de l'argument culturel comme stratégie judiciaire, pour la défense comme pour l'accusation ${ }^{51}$. Certains auteurs nuancent toutefois ce constat en avançant l'idée que,

\footnotetext{
${ }^{44}$ Gagné N., Guyon S., Trépied B., « Cultures à la barre. Regards croisés sur la justice civile outremer », Ethnologie française, ${ }^{\circ} 1,2018$, pp. 15-26.

${ }^{45}$ Belkacem L., "Quand la clinique fait l'ethnique ? Logiques performatives dans la médiation interculturelle pour familles migrantes », Genèses, vol. 1, n 98, pp. 47-68.

${ }^{46}$ D'hondt S., " Others on trial », op. cit.

${ }^{47}$ Coleman D. L., «Individualizing justice through multiculturalism: The liberals' dilemma », Columbia Law Review, vol. 96, n5, 1996, pp. 1093-1167.

${ }^{48}$ Wyvekens A., op. cit.

49 Terrio S. J., Judging Mohammed, Stanford, Stanford University Press., 2009, p. 25.

${ }^{50}$ Conception dont témoignent plus généralement le discours officiel niant l'existence de minorités « ethniques » et la difficile émergence d'un débat autour de la « question ethnique ».

${ }^{51}$ Wyvekens A., op. cit. Sur le cas belge, voir Simon C., Truffin B., op. cit.
} 
si la culture s'exprime globalement peu à l'audience, l'argument culturel n'est cependant pas dénué de force dans l'arène judiciaire ${ }^{52}$, où son efficacité juridique dépend avant tout de son énonciateur : disqualifié lorsqu'il est avancé par les justiciables (« selfculturalization $\left.^{53} »\right)$, il serait davantage légitime dans la bouche de leurs avocats (pour expliquer le passage à l'acte notamment) ${ }^{54}$.

Une première modulation de la " défense culturelle » vise ainsi à insister explicitement sur l'altérité fondamentale qui sépare les prévenus des normes de conduites en vigueur en France afin de plaider que l'infraction n'a pas été - et éventuellement ne peut être - perçue comme telle, car sa commission a été guidée et évaluée par d'autres principes que ceux des professionnels du droit ${ }^{55}$.

Il s'agit alors, pour les avocats, non de nier la réalité des faits (souvent difficilement contestables car objectivés par le travail policier) mais d'en relativiser la gravité en faisant de l'altérité culturelle un facteur d'aliénation et en plaidant l'impossibilité, pour les mis en cause, de s'émanciper de schémas culturels dont la force d'imposition outrepasserait de beaucoup le libre arbitre individuel. Assurant la défense d'un prévenu « rom », un avocat plaide ainsi l'appartenance de son client à la communauté « des tziganes qui ont ensemble des liens d'intérêt et des liens de famille, qui viennent du même village ou de la même région en Roumanie, ce qui aide à comprendre leur réaction ${ }^{56}{ }$ ” et livre un discours qui, tout en reproduisant nombre de clichés à l'encontre des « Roms », prétend à l'expertise ${ }^{57}$ :

« Depuis le XIII ${ }^{\mathrm{e}}$ siècle, c'est une communauté ségréguée qui vit à l'écart. Leur arrivée a été favorisée par l'ouverture des

\footnotetext{
${ }^{52}$ Bessière C., Biland E., Bourguignon A., Gollac S., Mille M., Steinmetz H., « Faut s'adapter aux cultures, Maître ! », Ethnologie française, $\mathrm{n}^{\circ} 1,2018$, pp. 131-140.

${ }^{53}$ D'hondt S., « Others on trial », op. cit., p. 807.

${ }^{54}$ Notons toutefois que les travaux sur la justice ultramarine y relèvent la reconnaissance de la « culture » des justiciables comme un enjeu légitime. Voir par exemple Gagné N., Guyon S., Trépied B., op. cit.

${ }^{55}$ Les développements qui suivent sur les stratégies de « défense culturelle » à l'audience sont pour partie issus d'une communication orale avec Lilian Mathieu : Darley M., Mathieu L., « Le proxénète au tribunal : entre figure morale et construction pénale ", Congrès de l'Association française de science politique, ST 26, Montpellier, Juillet 2017.

${ }^{56}$ Observation, Avocat de la défense, Procès Morariu, Mars 2015, par Lilian Mathieu.

${ }^{57}$ D'hondt S., « The Cultural Defense as Courtroom Drama: The Enactment of Identity, Sameness, and Difference in Criminal Trial Discourse », Law \& Social Inquiry, vol. 35, nº 1, pp. $67-98$ (p. 72).
} 
frontières mais ce n'est pas une population migrante, ils font des allers-retours. Leur histoire est étanche, le dossier ne dit rien d'eux, de leur histoire. Nous, gens de l'Ouest, quand on leur pose une question, ils ne peuvent pas répondre, ils ont une façon de penser différente de la nôtre, on ne peut pas leur tenir rigueur de leurs contradictions ${ }^{58}$.»

L'avocat fait ainsi entrer la différence culturelle à l'audience en établissant une distinction fondamentale entre le prévenu et lui, et plus largement entre le prévenu et la communauté des professionnels du droit qui ont à le juger, et en faisant de ce dernier un " Autre culturel impénétrable, dénué de parole et non émancipé ${ }^{59} »$. Dans le système perceptif ainsi constitué, le « majoritaire », dont l'avocat se fait le représentant, incarne l'universel, et le justiciable «minoritaire » le particulier $^{60}$. La différenciation culturelle, naturalisée et érigée en " principe explicatif ultime ${ }^{61}$ », est alors invoquée pour avancer le caractère inéluctable de la prostitution et du proxénétisme dans cette « communauté » de « très pauvres, très peu éduqués, [qui] n'ont pas la notion de victime ${ }^{62}$ ": «Dans cette communauté, toutes les femmes exercent la prostitution. La prostitution est présente dans les familles sans que leurs membres aient le sentiment de se livrer au proxénétisme ${ }^{63}$.

Dans le cas des procès pour proxénétisme impliquant des femmes proxénètes elles-mêmes prostituées, les avocats de la défense invoquent également comme facteur d'aliénation le partage par les prévenues d'une même condition genrée et sociale avec celles que la justice leur oppose comme « victimes ». Cette "identité de parcours » entre prévenues et victimes, et leur appartenance partagée à une communauté prostitutionnelle présentée comme vulnérable, sont directement rapportées à l'appartenance culturelle des justiciables et participent

\footnotetext{
${ }^{58}$ Observation, Avocat de la défense, Procès Morariu, Mars 2015, par Lilian Mathieu.

${ }^{59}$ D'hondt S., «The Cultural Defense as Courtroom Drama », op. cit., p. 71.

${ }^{60}$ Guillaumin C., L'idéologie raciste. Genèse et langage actuel, Paris, Gallimard, 2002 [1972] Dahhan R., Picot P., Trawalé D., Cossée C., Rabaud A., « Analyser des terrains contemporains à partir du couple notionnel "majoritaires/minoritaires" », Cahiers du genre, vol. 1, n68, pp. 145171.

${ }^{61}$ Jounin N., Palomarès E., Rabaud A., « Ethnicisations ordinaires, voix minoritaires », Sociétés contemporaines, vol. 2, $\mathrm{n}^{\circ} 70,2008$, pp. 7-23.

${ }^{62}$ Observation, Avocat de la défense, Procès Pietru, Mai 2016, par Muriel Mille et Alban Jacquemart.

${ }^{63}$ Observation, Avocate de la défense, Procès Antonescu, Juillet 2015, par Lilian Mathieu.
} 
donc d'un mouvement d'accentuation de l'altérité des prévenus à des fins d'atténuation de la gravité des faits. Ainsi, le passage de victime à auteure des prévenues nigérianes (qui, tout en continuant à se prostituer pour payer leur dette, font venir d'autres femmes du Nigéria afin de tirer profit de leur prostitution et d'accélérer le remboursement des sommes dues) est souvent invoqué dans les plaidoiries de la défense comme une spécificité de la traite nigériane, un changement de statut « culturellement » quasi inéluctable.

«Mme A. a été victime de ce réseau de prostitution. Elle a basculé de victime à une complicité objective du réseau. Elle accepte d'acheter une personne. Ici, c'est incroyable, mais au Nigéria, c'est monnaie courante. C'est comme ça qu'elle a été élevée. C'est comme ça que se fait la vie au Nigéria [...]. Mme A. fait tout pour s'en sortir, se réinsérer. La condamnation ne doit pas la freiner dans sa volonté de comprendre la conception de la femme en Occident ${ }^{64}$. »

Si la fabrique de l'altérité par l'invocation d'un différentialisme culturel qui séparerait les Nigérianes de l'Occident vise ici à atténuer la condamnation morale et pénale des juges, elle vient aussi rappeler l'extranéité première des prévenues à l'ordre moral " occidental» dominant et la nécessité pour elles de s'en rapprocher - démarche dans laquelle la justice doit les soutenir. Cette altérisation est ici renforcée par la mention récurrente et éminemment exotique des rituels de juju censés sceller, dans le pays d'origine, les ressorts de l'exploitation déployée sur le territoire français :

«Moi j'ai trouvé que c'était une spécificité de ces dossiers-là, cet aspect culturel [...] Je trouve ça dommage que les juges se soient débarrassés de cet argument-là en disant "irrecevable", quoi. Parce que deux ans de relation client-avocat avec Mme X m'ont fait dire que oui, bien sûr que ça avait joué quoi. Et le fait même du juju... n'importe quel avocat, euh... vous lui auriez présenté ça, il aurait trouvé ça drôle. En fait, c'est ça la difficulté : c'est que vous êtes avocat, vous devez essayer de vous mettre à la

\footnotetext{
${ }^{64}$ Observation, Avocat de la défense, Procès Onwudiwe, Octobre 2016, par Mathilde Darley.
} 
place de votre client et vous voyez qu'il y a un... un vrai fossé culturel. Les sorciers, les choses comme ça ${ }^{65} \ldots$ »

Facteur d'aliénation, l'appartenance culturelle est cependant également avancée comme source d'ignorance. Ainsi le brouillage dit « culturel » des frontières entre "prostituée » et «proxénète » est-il mis en avant pour attester de la «bonne foi » des justiciables et de leur incapacité à saisir le cadre de la loi :

"Quand on l'interroge sur ses fonctions, c'est compliqué pour [sa cliente] de dire que c'est Mme D qui était le patron. Elle ne peut pas mettre Mme D en cause comme ça. C'est culturel. Elle était prostituée il y a quinze jours, là elle est proxénète. Il y a une fiche de paie pour une masseuse. Ce sont des éléments qui démontrent que cette femme ne voulait pas échapper à la loi. Son but est d'avoir un emploi stable et d'élever son enfant. Pour elle, la masturbation n'est pas un acte sexuel ${ }^{66}$.»

De même, plaider que les «finitions manuelles », c'est-à-dire les pratiques masturbatoires à l'issue d'un massage, ne sont pas perçues comme relevant à part entière de la sexualité dans la culture chinoise permet aux avocats de la défense de relativiser la dimension prostitutionnelle de l'activité et, partant, la qualification de proxénétisme associée à son organisation : c'est sans connaître les normes qui prohibent de tirer profit d'actes qu'elles-mêmes ne perçoivent pas comme sexuels, que les masseuses mises en cause pour proxénétisme se sont engagées dans les activités du salon.

"C'est un massage comme en Chine, où ce n'est pas répréhensible! Quand vous dites à une masseuse que c'est une prostituée, que c'est une putain, elle, elle dit "non, on masse". Ce qui se passe dans le salon, ça fait objet de débat. L'arrêt de 1996 de la cour de cassation sur la prostitution chinoise, c'est sur une autre planète : "le fait de pratiquer des caresses allant jusqu'à l'éjaculation!" Donc s'il n'y a pas d'éjaculation, ce n'est pas de la prostitution! Les juristes se cassent la tête : une femme à poil

\footnotetext{
${ }^{65}$ Entretien, Jeanne Elvire, Avocate de la défense, 27/11/2018, par Mathilde Darley.

${ }^{66}$ Observation, Avocat de la défense, Procès Chen, Mars 2015, par Gwénaëlle Mainsant.
} 
c'est une prostituée ? On lit l'arrêt de la cour de cassation et on reste perplexe ${ }^{67}$.

La « culture » des prévenus peut cependant également être invoquée par les avocats de la défense (mais aussi par les prévenus eux-mêmes) pour au contraire mettre à distance le particularisme culturel qui semble spontanément associé à leur origine : il s'agit alors, pour la défense, de rapprocher la culture des prévenus des schémas normatifs pensés comme dominants dans la culture des magistrats (hommes blancs et femmes blanches, membres des catégories socio-professionnelles supérieures).

Ainsi, l'insistance sur la sincérité des sentiments liant le prévenu (proxénète) à celle que la justice lui oppose (sa compagne prostituée), attestée par des images (sur les comptes Facebook notamment) ou des mots tendres entre conjoints (dans les écoutes téléphoniques) ${ }^{68}$, vise à réinscrire les relations familiales et conjugales des prévenus dans les normes classiquement attendues de la conjugalité hétérosexuelle. Plus encore, tandis que l'accusation voit dans le proxénète oisif et violent associé au prévenu « rom » l'idéaltype de la «domination masculine», les avocats insistent au contraire sur la division égalitaire et consentie du travail au sein du couple, dans lequel les hommes endossent par ailleurs des rôles dont la division sexuée du travail les avait longtemps tenus à l'écart.

« Vous constaterez que les enfants ont bien été nourris et c'est Monsieur qui s'en occupe ! Il essaye de les élever le mieux $\operatorname{possible}^{69} ! »$

À rebours de l'image de prévenus « roms » incarnant une forme d' " arriération », en matière de rapports sociaux de sexe notamment, dans les arguments culturalistes invoqués par les magistrats, la division du travail mise en avant ici et la bonne tenue de son rôle de père par l'homme du couple permettent au contraire de rapprocher le fonctionnement de la cellule conjugale et familiale d'un modèle généralement présenté comme celui d'une société occidentale éclairée, berceau de l'émancipation féminine. L'identité d'honnête travailleur

\footnotetext{
${ }^{67}$ Observation, Avocat de la défense, Procès Yang, Mai 2015, par Gwénaëlle Mainsant.

${ }^{68}$ Voir aussi G. Favarel-Garrigues et L. Mathieu, dans ce numéro.

${ }^{69}$ Observation, Avocat de la défense, Procès Tampiar, Mars 2016, par Mathilde Darley.
} 
constitue un autre des leviers fréquemment activés pour rapprocher la « culture » des prévenus de celle des magistrats. Lorsqu'ils sont invoquées par les avocats de la défense à propos de leurs clients, le " sens du travail » et la " solidarité ${ }^{70}$ ", régulièrement prêtés à la communauté chinoise par l'ensemble des professionnels du droit, permettent ainsi de rebattre les cartes de l'altérité et de ses effets sur l'évaluation des prévenus : leur mise en avant dote en effet les conduites d'une rationalité non seulement audible par les magistrats, mais dont la charge morale positive semble venir en partie minorer le processus d'altérisation par ailleurs à l'œuvre à l'égard des étrangers mis en cause.

« Ce sont les valeurs transmises par ses parents : le travail et le sport. [...] Monsieur a un sens moral et des vraies valeurs, il ne s'est pas égaré de ce point de vue-là, il a toujours travaillé en tant que cuisinier et c'est un très bon cuisinier ${ }^{71}$. »

En avançant la différence culturelle comme argument de défense, les avocats de la défense, même s'ils s'autorisent à faire bouger les lignes du système de normes invoqué (et de la distance / proximité des justiciables à son égard) en fonction de la stratégie de défense retenue, reproduisent pourtant l'idée d'une ligne de fracture entre " eux » et « nous » et la position hégémonique de la culture dont ils s'érigent en représentants ${ }^{72}$, au même titre que les magistrats. Se plaçant dans une position surplombante censée leur permettre d'accéder à une connaissance objective des choses, les acteurs du droit se pensent en fait comme " non racialisables ${ }^{73}$ » au sein d'une arène où la culture et l'origine sont invoquées pour hiérarchiser les groupes et structurer la place sociale qui leur est assignée, signant les processus de racialisation dont elle est tributaire.

"C'est pas la même culture qui fait qu'on n'a pas la même forme de proxénétisme » : le rôle de l'origine dans l'appréhension des faits et la construction du jugement pénal

\footnotetext{
${ }^{70}$ Voir aussi G. Favarel-Garrigues et L. Mathieu, dans ce numéro.

${ }^{71}$ Observation, Avocat de la défense, Procès Sun, Septembre 2015, par Gilles Favarel-Garrigues et Muriel Mille.

${ }^{72}$ D'hondt S., « The Cultural Defense as Courtroom Drama », op. cit., p. 72.

${ }^{73}$ Voir Mazouz S., op. cit., p. 43.
} 
Si les magistrats du siège comme du parquet s'abritent a priori, en entretien, derrière l'argument d'un traitement égalitaire de leurs publics pour mettre à distance toute lecture culturaliste des faits ou des prévenus, la typologie de l'exploitation sexuelle qu'ils établissent généralement spontanément au cours de l'échange avec les chercheurs segmente pourtant l'infraction en fonction de l'origine prêtée aux justiciables. La mention de la dimension culturelle de la prostitution et/ou de la traite par les procureurs interrogés s'accompagne ainsi, à l'audience, de longs réquisitoires insistant, à l'instar des plaidoiries de la défense évoquées ci-dessus, sur l'expertise culturelle nécessaire à la compréhension de l'infraction. Celle-ci est cependant convoquée non à des fins de " défense culturelle », mais au contraire pour accentuer le caractère inéluctable de l'exploitation et la nécessité de sanctionner lourdement ses auteurs. Les usages du culturalisme chez les magistrats du parquet ayant été développés ailleurs ${ }^{74}$, c'est davantage sur leur place dans la construction et la justification du jugement par les juges du siège que j'insisterai ici.

Bien qu'elle reconnaisse n'avoir eu que peu de dossiers de traite ou proxénétisme à connaître, cette présidente de chambre souligne ainsi en ouverture de l'entretien les spécificités de la traite nigériane, qu'elle juge (sur la base de la seule affaire qu'elle ait eue à juger) plus grave, car présentant des formes d'exploitation plus poussées, que les dossiers «brésiliens » ou « de l'Est » :

«Les Nigérianes, c'est une traite que je trouve proche de l'esclavage parce que ce sont des filles qui sont sur de la prostitution de trottoir, près des gares, avec des conditions... Des prix de prestations très faibles, avec la nécessité d'en faire beaucoup pour rembourser une dette ${ }^{75}$.»

Interrogée plus spécifiquement sur le poids des variables culturelles dans le jugement, elle récuse certes toute hiérarchisation des dossiers fondée sur l'appartenance culturelle des prévenus, mais confirme cependant la prégnance des " éléments culturels » à l'audience et la nécessité pour les juges de les « entendre », illustrant l'ambiguïté dans

\footnotetext{
${ }^{74}$ Darley M., « Le proxénétisme en procès : la réaffirmation d'un ordre sexuel national ? », in G. Girard, I. Perreault, N. Sallée (dir.), Sexualité, savoirs et pouvoirs, Montréal, Presses Universitaires de Montréal, 2019, pp. 155-165.

${ }^{75}$ Entretien, Catherine Rougelot, Juge, 7/12/2015, par Lilian Mathieu.
} 
laquelle les acteurs de la justice se trouvent pris : soucieux de respecter l'injonction républicaine qui leur est faite de " rester aveugles aux particularismes des individus ${ }^{76} »$, ils se sentent néanmoins le devoir de tenir compte, pour mieux les neutraliser, des éléments considérés comme des marqueurs culturels.

« Alors je pense qu'on essaie à l'audience de pas fonctionner en clichés, hein. Après, dans la justice on a beau faire, ça peut être subjectif. Moi je... Non moi c'est vrai que je vous dis Nigérianes, Brésiliennes, Bulgares... Sincèrement à l'audience je pense qu'on l'appréhende au cas par cas le dossier, on ne compare pas. On est forcément obligés de tenir un peu compte de la culture, je prends l'exemple de mes Brésiliennes qui d'elles-mêmes expliquaient qu'elles choisissaient de se prostituer parce que elles gagnaient mieux leur vie en se prostituant qu'en faisant un boulot de femme de ménage ou de serveuse. On est obligé de l'entendre, ça. Chez les Nigérianes on est bien obligé de l'entendre que parfois c'est les familles qui entre guillemets ont plus ou moins vendu leur fille. Après quand on voit, au moment de la sanction, si les faits rentrent dans le cadre de la loi, j'ai envie de vous dire ces fameux éléments culturels à ce moment-là on tient pas compte d'eux, on tient compte des faits concrètement par rapport à la loi. Mais à l'audience ça ressort. À l'audience les gens parlent de leur culture, bien sûr. Et d'ailleurs nos fameux proxénètes d'Europe de l'Est c'est souvent ce qu'ils vont dire. Ils vont dire "mais chez nous c'est normal la prostitution", voilà ce qu'ils nous disent ${ }^{77}$.»

Outre qu'il illustre singulièrement le paradoxe de l'universalisme républicain chez les magistrats, " pris entre la volonté de "comprendre" l'Autre dans ses différences et une approche égalitariste institutionnelle ${ }^{78} »$, cet extrait d'entretien souligne donc également la centralité des catégorisations fondées sur l'appartenance dite culturelle des personnes mises en cause. Les classements sociaux opérés à partir de l'appartenance culturelle supposée des justiciables, et qui découlent

\footnotetext{
${ }^{76}$ Potot S., « Accueillir des enfants dits "Roms roumains" dans l'école républicaine. Le système éducatif français face à la catégorisation socioculturelle ", Agora débats/jeunesse, vol. 1, n 84 , 2020, pp. 53-66.

${ }^{77}$ Entretien, Catherine Rougelot, Juge, 7/12/2015, par Lilian Mathieu.

${ }^{78}$ Potot S., op. cit., p. 55.
} 
in fine de l'origine qu'on leur prête, semblent en effet érigés en déterminants à la fois routiniers et fondamentaux des interactions entre justice et justiciables et, au-delà, de définition et d'interprétation des situations exposées à l'audience.

« Je ne dis jamais "vous mentez" à un prévenu... sauf à un Roumain. Pour les Roumains, vous les flattez. Pour un Roumain, ça fait partie de sa culture, il ment, il est flatté. C'est très étonnant. [...] On est obligé de s'adapter à la culture qu'on juge $^{79} \ldots »$

Rappelant les formes d'ethnicisation ordinaire des rapports sociaux observées ailleurs ${ }^{80}$, les magistrats ayant à juger des affaires de traite ou de proxénétisme réinscrivent donc régulièrement, à l'audience et en entretiens, les justiciables étrangers dans une tradition culturelle différente pour expliquer tant les logiques de commission de l'infraction que les comportements jugés incongrus à l'audience ${ }^{81}$.

« Je pense qu'il y a aussi un problème culturel, moi j'aime bien la logique cartésienne et là, en les écoutant répondre, je me suis dit que la logique chinoise n'était pas la logique cartésienne française ${ }^{82}$. »

En l'absence de « formation sur la culture des gens qu'on a en face de soi $»^{83}$, formation pourtant jugée nécessaire, les magistrats disent alors s'adapter $^{84}$, à partir de leur expérience de terrain, aux particularismes culturels des personnes mises en cause pour proxénétisme.

« Je vous mentirais en disant que j' ai suivi des cours sur la culture chinoise. Mais il se trouve qu'à force de voir passer des personnes chinoises, bon ben on commence un peu à s'intéresser. Par exemple, moi, j'ai appris que euh... il est impossible, il n'y a pas de mots pour dire : "non" ou "oui" en Chinois. Ça se dit pas.

\footnotetext{
${ }^{79}$ Entretien, Roselyne Duverne, Juge, 26/03/2015, par Gwénaëlle Mainsant.

${ }^{80}$ Jounin N., Palomarès E., Rabaud A., op. cit.

${ }^{81}$ Pour des observations sur le rôle joué par l'invocation de la culture des justiciables dans d'autres arènes juridiques, voir par exemple Terrio S. J., op. cit. ; Bessière C., Biland E., Bourguignon A., Gollac S., Mille M., Steinmetz H., op. cit. Ou Bessière et al. ?

${ }^{82}$ Entretien, Véronique Trion, Juge, 4/11/2014, par Mathilde Darley et Gwénaëlle Mainsant.

${ }^{83}$ Entretien, Magali Castillon, Juge, 5/05/2016, par Mathilde Darley et Muriel Mille.

${ }^{84}$ Voir aussi Bessière C. et al., op. cit.
} 
Le non n'existe pas. Donc, si vous vous attendez à ce que la personne vous dise non, ça va pas être possible. Et qu'on a toujours l'impression qu'ils font des périphrases ou tout ça, mais c'est une question de culture [...] Je pense que c'est vraiment pas du tout la même culture qui fait qu'on n'a pas la même forme de proxénétisme ${ }^{85}$.»

Si ces extraits d'entretien illustrent la " prégnance banale et routinière des classements sociaux fondés sur l'origine ${ }^{86}$ " dans la pratique professionnelle des juges, leur déploiement à l'audience invite à réfléchir à leur articulation à d'autres rapports sociaux, et notamment aux rapports sociaux de race et de genre, et aux formes de domination dans lesquels ils s'inscrivent.

Déclinant les types de proxénétisme en fonction de l'appartenance culturelle des prévenus, les discours des magistrats semblent en effet renseigner davantage sur les attendus, notamment genrés, de la culture pensée comme majoritaire que sur les particularismes culturels prêtés aux prévenus. La " culture rom », décrite comme irriguée par l'alcool, la vulgarité, l'oisiveté et la violence, mais aussi l'absence de tabous sexuels et d'interdits moraux, et notamment ceux de l'inceste et l'exploitation sexuelle intra-familiale, donnerait ainsi lieu, dans les propos des magistrats, à des formes de proxénétisme « particulièrement choquantes $^{87} »$. Le fait que, dans nombre de procès observés, les femmes assurent les revenus du foyer par leur prostitution pour le compte de leur compagnon, en brisant le tabou de la prostitution intraconjugale, bouleverse plus largement les canons de la «bonne conjugalité $^{88} \gg$ : ceux-ci apparaissent notamment définis par l'exclusivité sexuelle, la protection des femmes par leurs maris ou encore l'inscription de la relation conjugale dans un lexique amoureux choisi $^{89}$. Juges et procureurs mettent ainsi fréquemment en tension, en les présentant comme moralement incompatibles, l'activité de proxénétisme et la sexualité prostitutionnelle d'une part, et les

\footnotetext{
${ }^{85}$ Entretien, Magali Castillon, Juge, 5/05/2016, par Mathilde Darley et Muriel Mille.

${ }^{86}$ Jounin N., Palomarès E., Rabaud A., op. cit., p. 13.

${ }^{87}$ Observation, Procès Tampiar, Mars 2016, par Mathilde Darley.

${ }^{88}$ Sur la notion de bonne conjugalité, voir aussi Verjus A., Le bon mari. Une histoire politique des

hommes et des femmes à l'époque révolutionnaire, Paris, Fayard, 2010.

${ }^{89}$ Voir Favarel-Garrigues G., Mathieu L., dans ce numéro.
} 
sentiments amoureux d'autre part : comment un homme réellement épris saurait-il tolérer que sa compagne se prostitue?

« J'ai lu toutes les écoutes, j'attends encore de voir où Monsieur va dire [à sa compagne prostituée] : "Arrête mon amour, je vais te protéger, rentre ${ }^{90 " !} ! »$

Mais se trouve également, plus largement, remis en cause un modèle conjugal dont les avocats de la défense s'attachent, comme on l'a vu, à souligner le caractère "progressiste » mais dont les magistrats soulignent au contraire qu'il déroge à la division sexuelle " classique » du travail : " Pourquoi, et sans tenir des propos sexistes, [le prévenu] ne propose pas [à son épouse prostituée] de rester à la maison s'occuper des enfants et d'aller lui-même travailler ${ }^{91}$ ?»

Alors que les activités de proxénétisme elles-mêmes n'occupent qu'une place marginale dans les débats dont il est ici question, marginalité qui peut s'expliquer par l'inconfort des magistrats à l'égard de formes d'exploitation intra-conjugales, ce sont davantage les manières de dire et de faire le couple, par ailleurs socialement marquées, qui retiennent l'attention des magistrats et trahissent leur ethnocentrisme : jugeant à l'aune de leurs propres valeurs, ces derniers se font ainsi porteurs d'une vision de la conjugalité qui marque définitivement le rejet des prévenus hors de la culture des magistrats, pensée comme " majoritaire ». La position endossée ici par ces derniers rappelle alors celle des militants anti-traite étudiés par Elizabeth Bernstein, promouvant une vision de la sexualité " maintenue dans les limites du couple romantique », et pourfendant du même coup, implicitement, les formes non-familiales de sexualite ${ }^{92}$.

Dérogeant également à l'ordre genré, les femmes recourant à l' " achat » d'une autre femme afin de rembourser plus vite leur propre dette, phénomène présenté par les professionnels du droit comme «typique » de la «communauté nigériane », invalident les représentations dominantes $\mathrm{du}$ " proxénète pur » comme un homme violent exploitant

\footnotetext{
${ }^{90}$ Observation, Président, Procès Tampiar, Mars 2016, par Alban Jacquemart et Muriel Mille.

${ }^{91}$ Ibid.

${ }^{92}$ Voir le texte d'E. Bernstein dans ce numéro ; Bernstein E., « Carceral politics as gender justice? The "traffic in women" and neoliberal circuits of crime, sex, and rights ", Theroy and Society, vol. 41, 2012, pp. 233 - 259.
} 
la sexualité de femmes victimes, et dont le comportement serait donc à interpréter au prisme de la domination masculine ${ }^{93}$.

« Le proxénète pur mais c'est celui qui impose - enfin pur, il est pas pur. On va dire méchant, quoi. Voilà, celui qui fait que le dossier est glauque. [...] Y a des dossiers qui sont sordides de chez sordide parce que on a des types qui ne font rien, qui ne font que des pressions sur des filles et qui en plus ne leur laissent même pas la moitié de leur argent. Des filles qui ont à peine de quoi se payer à manger ${ }^{94}$. »

Dans le cas du proxénétisme et de la traite nigérians, l'évocation de pratiques liées au juju et présentées comme occultes, intrusives (tel le prélèvement de poils pubiens ou de sang) et éminemment exotiques semblent attester d'une inexorable distance culturelle : les prévenues sont alors présentées comme évoluant hors des référentiels culturels et genrés des magistrats, mais aussi, plus généralement, hors de leurs repères normatifs distinguant le bien du mal.

« Il y a une identité de parcours entre les prévenues et les victimes. Malgré cela, il faut distinguer, premièrement, les prévenues qui ont commis, qui ont choisi de reproduire le schéma et d'exploiter des êtres humains, et deuxièmement, les victimes qui ont dénoncé. Il faut donc non seulement briser le réseau, mais sanctionner le basculement ${ }^{95}$.»

Alors que le cadre abolitionniste français associe spontanément l'identité de « victime » à la condition prostituée et semble donc justifier la perception des travailleuses du sexe nigérianes comme avant tout victimes et, partant, entravées dans l'exercice de leur libre arbitre, c'est pourtant leur implication dans la commission d'une infraction qui non seulement prime ici, mais se trouve même redoublée par leur statut de " victime "- les rejetant définitivement hors de la culture des professionnels du droit et de la politique compassionnelle promue par les politiques publiques nationales à l'égard des femmes engagées dans le commerce du sexe.

\footnotetext{
${ }^{93}$ Voir aussi G. Favarel-Garrigues et L. Mathieu dans ce numéro.

${ }^{94}$ Entretien, Catherine Rougelot, Juge, 7/12/2015, par Lilian Mathieu.

${ }^{95}$ Observation, Procureur, Procès Onwudiwe, Octobre 2016, par Mathilde Darley.
} 
Ainsi, tandis que la référence récurrente à la culture prétendument associée à l'origine des justiciables comme des victimes permet aux avocats de construire une "défense culturelle ${ }^{96}$ ", elle semble venir étayer, chez les magistrats, la hiérarchisation des affaires et la qualification des faits en facilitant la mise en correspondance entre un acte ou un comportement jugé déviant d'une part, et une définition pénale souvent abstraite de l'infraction concernée correspondant d'autre part. Qu'elle soit invoquée en soutien à une stratégie de défense ou d'accusation, la culture des justiciables comme des victimes, et sa convocation routinière par les acteurs du droit en entretien comme à l'audience, semble donc également permettre de réaffirmer l'existence d'un entre-soi « culturel » entre des professionnels que leurs positions dans l'arène judiciaire opposent a priori. Autrement dit, elle offre un socle stable, avec les autres formes d'assignations (de genre notamment) dont elle permet le déploiement, à la production d'un consensus, voire d'une connivence entre les acteurs du droit ${ }^{97}$. En réifiant les trajectoires sociales, elle donne par ailleurs « un semblant de stabilité informationnelle ${ }^{98}$ " à une infraction que son caractère international et l'inconfort qu'elle suscite en droit français rendent difficile à appréhender pour les acteurs du droit. Autrement dit, les stéréotypes convoqués par les avocats comme par les magistrats, outre qu'ils contribuent à produire la différence sous couvert d'œuvrer à sa meilleure compréhension, constituent de facto une partie du savoir empirique sur laquelle s'appuie l'action de juger : ils assurent en effet la " compréhension immédiate, circonstancielle ${ }^{99}$ » de faits et de situations marqués par le flou et l'incertitude juridiques entourant leur définition.

\footnotetext{
${ }^{96}$ Coleman D. L., op. cit.

${ }^{97}$ Les « traits d'humour » (ou présentés comme tels) culturalistes qui ponctuent l'audience, et ne sont généralement pas traduits par les interprètes aux prévenus, l'illustrent avec force en rappelant la connivence existant de facto entre les parties se pensant comme appartenant à une même culture. Une présidente de chambre multiplie ainsi, au cours de l'audience d'un procès pour proxénétisme impliquant des ressortissants chinois, des références voulues comiques, mais ouvertement racistes, à la culture des prévenus : après avoir désigné le flou entourant les faits et leur récit par les accusés de véritable « mystère de la chambre jaune », elle reproche à un prévenu d'être « adepte du supplice chinois » en raison de la non adéquation des réponses qu'il fournit depuis le début de l'audience aux questions des magistrats (Observation, Procès Li, Novembre 2014, par Mathilde Darley et Gwénaëlle Mainsant). Sur l'humour comme «forme sédimentée, ordinaire et banalisée de l'assignation raciale », voir par exemple Mazouz S., op. cit., p. 22.

${ }^{98}$ Jounin N., op. cit.

${ }^{99}$ Ibid.
} 
Du « problème culturel " à " l'atteinte aux valeurs de la République » : l'argument culturel au service du gouvernement des frontières

Les procès pour proxénétisme aggravé et/ou traite des êtres humains mettent en scène des populations, prévenus et victimes, que leur situation socio-économique majoritairement défavorisée, leur statut d'étranger (le plus souvent sans titre de séjour), et l'activité prostitutionnelle et/ou d'exploitation de la prostitution à l'origine de leur comparution devant les tribunaux placent de facto aux confins juridiques, mais aussi socio-économiques et moraux de la société. Le jugement pénal en matière d'exploitation sexuelle permet ainsi d'éclairer d'une lumière particulière les marges de la société et ce qu'elles disent de l'ordre public républicain autour duquel elles se construisent.

«Un, rien ne les oblige à venir en France et deux, on peut venir aussi en France en essayant de se mettre en situation régulière. [...] Si on décide de venir en France, c'est pour s'intégrer à la société française. Par rapport à cela, il faut commencer par faire en sorte de se retrouver en situation régulière, faire les démarches et les efforts, déjà $[\ldots] \mathrm{Y}$ a quand même un minimum qui est d'apprendre à parler français, c'est quand même un minimum, or on voit quand même des personnes qui au bout de dix ans en France ne parlent pas un mot de français et n'ont manifestement fait aucun effort pour vouloir parler français ! ça c'est une démarche, je veux dire que c'est une volontét ${ }^{100} ![\ldots] »$

Le juge Delcroix, représentant de l'institution judiciaire et incarnant à ce titre l'ordre national et sa préservation, donne ainsi à voir l'articulation entre " pensée d'État » et immigration (analysée par Abdelmalek Sayad) en appuyant son argumentaire sur la double perturbation qu'induisent les délinquants d'origine étrangère : une " faute de situation historique ", imputable au simple caractère « déplacé » que présenterait la présence immigrée au sein d'un ordre national républicain pensé comme (linguistiquement, culturellement, etc.) homogène ; et une faute " comportementale », sanctionnable et sanctionnée par le Code pénal et traitée "dans sa matérialité » par

\footnotetext{
${ }^{100}$ Entretien, Etienne Delcroix, Juge, 03/02/2016, par Mathilde Darley et Gilles Favarel-Garrigues.
} 
l'instance judiciaire ${ }^{101}$. Le juge Delcroix rappelle donc que l'immigré, étranger à l'ordre institué, est tenu à une sorte d' "hypercorrection » non seulement sociale ${ }^{102}$, mais aussi - et surtout - morale. Car c'est ici davantage d'arguments moraux (" faire l'effort », « vouloir parler français ", etc.) que d'arguments juridiques que ce Président de chambre fait usage pour justifier la sévérité qu'il prône par ailleurs à l'encontre des mis en cause. Pour les juges, la maîtrise insuffisante du français justifie ainsi, comme chez le juge Delcroix, l'activation de deux ressorts classiques de disqualification morale des étrangers : d'une part, leur absence de volonté d'intégration à la société française, et d'autre part la « charge » (financière en particulier, à travers le coût de l'interprétariat) qu'ils et elles feraient peser sur la société d'accueil ${ }^{103}$.

La Présidente à la prévenue, qui annonce avoir besoin de l'interprète après avoir dit apprendre le français en prison : «Ben faut bien suivre les cours hein, parce que là pour le français c'est pas encore ${ }^{104} \ldots »$

Si le « débordement moral » du droit des étrangers sur d'autres sphères de la justice a pu être mis en évidence ailleurs ${ }^{105}$, la nature de l'infraction semble ici lui offrir des conditions d'épanouissement particulières, soulignées par les juges.

" Y'a un truc qui est dur parce que comme ces dossiers sont souvent glauques, avec en quelque sorte des sales personnes et puis des personnes vulnérables, on pourrait avoir tendance finalement à trop moraliser à l'audience ${ }^{106}$. »

Bien que les juges se défendent, en entretien, de céder à la « tentation » de la «morale judéo-chrétienne » pour lui préférer un jugement " concret sur les faits ${ }^{107}$ ", l'engagement des prévenus comme des victimes dans des formes prostitutionnelles de sexualité et/ou dans leur

\footnotetext{
${ }^{101}$ Voir Sayad A., «Immigration et "pensée d'Etat" », Actes de la recherche en sciences sociales, vol. 129, 1999, pp. 5-14 (p. 8).

${ }^{102}$ Ibid., p. 10.

${ }^{103}$ Darley M., « Traduire la culture dans les procès pour traite », Plein Droit, $\mathrm{n}^{\circ} 124,2020$, p. 3336.

${ }^{104}$ Observation, Procès Afamefuna, Mai 2018, par Mathilde Darley.

${ }^{105}$ Simon C., Truffin B., op. cit.

${ }^{106}$ Entretien, Catherine Rougelot, Juge, 7/12/2015, par Lilian Mathieu.

${ }^{107}$ Ibid.
} 
organisation semble de facto fournir une surface de projection aux jugements d'ordre moral quant aux motivations de départ du pays d'origine et à leur légitimité à séjourner sur le territoire français.

« Dire qu'on est victime effectivement du fait qu'on est en situation irrégulière sur le territoire, c'est vrai, c'est objectif, mais je dirais on est aussi d'une certaine façon victime de son propre comportement ! C'est-à-dire que la personne a quand même encore la possibilité finalement de retourner dans son pays si elle considère ou elle s'aperçoit qu'elle n'a pas la possibilité de régulariser sa situation en France. [...] Est-ce qu'il est pire pour ces gens-là de vivre en Chine ou de se retrouver sur les trottoirs de Belleville ? Moi je sais pas. Apparemment beaucoup préfèrent se retrouver sur les trottoirs de Belleville, là j'avoue que je m'interroge, c'est clair... Là aussi, tout ça est au cas par cas parce que la situation d'un réfugié qui quitte un territoire en guerre n'est pas la même que celle qui quitte un pays simplement parce que le niveau de vie ou les conditions de vie sont relativement moins évidentes que chez nous ${ }^{108} \ldots$ »

Le partage fréquent d'une même condition prostituée, mais aussi généralement d'une même irrégularité de séjour, par les prévenues et les victimes conduit alors, comme dans les propos de ce magistrat, à brouiller les frontières morales séparant habituellement la victime de l'auteur de l'infraction. Alors que la figure «pure »du réfugié ${ }^{109}$, victime de violences politiques et/ou fuyant un pays en guerre, permettrait éventuellement le déploiement d'une politique compassionnelle ${ }^{110}$, celle de la femme « choisissant» de s'adonner à la prostitution sur les trottoirs français plutôt que de supporter des conditions de vie économiquement difficiles dans son pays est plus ambigüe : elle vient ainsi souligner la force signifiante, pour l'interprétation des situations, du genre et de la sexualité, et des rapports de pouvoir socio-économiques dans lesquelles ils sont pris. Oscillant entre le stéréotype de la femme vénale troublant l'ordre public et moral et celui de l'étrangère coupable de séjour irrégulier ${ }^{111}$, la prostituée

\footnotetext{
${ }^{108}$ Entretien, Etienne Delcroix, Juge, 03/02/2016, par Mathilde Darley et Gilles Favarel-Garrigues. ${ }^{109}$ Malkki Lisa H., Purity and Exile: Violence, Memory, and National Cosmology among Hutu Refugees in Tanzania, Chicago, The University of Chicago Press, 1995.

${ }^{110}$ Fassin D., La raison humanitaire : une histoire morale du présent, Gallimard, Paris, 2010.

${ }^{111}$ Jakšić M., op. cit.
} 
étrangère apparaît comme une figure nettement plus trouble que celle, que semblent chercher les magistrats, de « victime idéale ${ }^{112}$ » innocente, trompée et abusée, et « dont les intérêts se démarqueraient clairement de ceux du délinquant » proxénète ${ }^{113}$. Dans le cadre abolitionniste français, la disposition des femmes à s'adonner à des formes de sexualité tarifée reste, en dépit d'une définition internationale et nationale de la traite rappelant le caractère inopérant de la notion de « consentement», un marqueur essentiel de l'infraction et de sa gravité. Or cette disposition est largement présentée comme corrélée à l'origine des femmes, et au rapport au corps et à l'argent que celle-ci induirait.

«La pauvre fille qu'on va récupérer dans un bled au fin fond de l'Afrique noire, qu'on amène en Europe en lui faisant croire n'importe quoi, en la menaçant, on la met sur les trottoirs de chez nous au bois de Boulogne, et puis avec des macs qui sont là en train d'essayer de rentabiliser au maximum, qui traitent ces filles comme de la viande, ça pour moi c'est l'archétype de la victime, où la question se pose pas, et puis par contre là où on s'interroge c'est les jeunes femmes qu'on voit là, qui elles manifestement ont un rapport à l'argent qui fait que entre gagner de l'argent et avilir entre guillemets leur corps elles ne se posent même pas la question! Donc c'est ce que je vous disais tout à l'heure, c'est le problème de la dé-fi-ni-tion. Ça c'est quand même extrêmement important puisque par rapport à la définition de la victime, le regard que l'on porte sur celui qui est censé l'exploiter est totalement différent ${ }^{114}$ ! »

S'il n'est donc pas possible de réaliser, à partir du corpus mobilisé ici, une étude de sentencing mettant statistiquement en perspective l'origine des justiciables et les peines encourues, force est pourtant de constater que l'appartenance culturelle prêtée aux justiciables vient nourrir la hiérarchisation morale de l'infraction, de ses victimes et de ses auteurs. L'interprétation juridique des faits et la politique pénale dont ils font l'objet se trouvent en effet largement rabattues sur une explication culturelle : les femmes africaines sont alors souvent

\footnotetext{
${ }^{112} \mathrm{Ibid}$.

${ }^{113}$ Lemonne A., Nagels C., « Traiter la traite : quand la prostituée navigue dans les eaux troubles de la dignité humaine ", in Adam C., De Fraene D., Mary P., Nagels C., Smeets $S$. (dir.), Sexe et normes, Bruxelles, Bruylant, 2012.

${ }^{114}$ Entretien, Etienne Delcroix, Juge, 03/02/2016, par Mathilde Darley et Gilles Favarel-Garrigues.
} 
considérées comme "archétypes de la victime », car supposément moins « consentantes », tandis qu'on prête communément au contraire aux autres étrangères impliquées dans le travail du sexe un rapport dégradé et avili à leur corps et à leur sexualité, venant minorer la gravité de l'infraction reprochée à leurs proxénètes. C'est sur cette mise en ordre culturelle des justiciables que s'appuient ensuite, pour partie au moins, la qualification de l'infraction (traite ou proxénétisme) et la peine encourue : ainsi, conformément à ce schéma interprétatif, la qualification de traite des êtres humains, si elle est systématiquement retenue dans les procès mettant en scène des protagonistes originaires d'Afrique, est généralement absente ou abandonnée en cours d'instruction ou d'audience dans le cas des procès impliquant d'autres ressortissants, roumains ou chinois notamment. Empruntant à l'imaginaire de l'esclavage (par ailleurs régulièrement convoqué dans les procès comme dans les colloques dédiés à la question de l'exploitation sexuelle), cette interprétation, reposant sur un découpage et une hiérarchisation culturelles et ethnoraciales de l'infraction, fait également le lit d'une politique de gouvernement des frontières nationales.

Le rappel régulier, à l'audience, de l'expulsabilité des justiciables, vient réaffirmer la centralité du contrôle des frontières dans la "pensée d'État », dont la mise au ban de l'ordre national constitue une des prérogatives essentielles ${ }^{115}$. Dans son délibéré, une Présidente de chambre, rappelant l'inviolabilité et la supériorité de l'ordre républicain national, s'appuie ainsi sur le rejet d'une " défense culturelle » pour justifier sa décision d'assortir la quasi-totalité des condamnations prononcées d'interdictions définitives de séjour sur le territoire français, ainsi purgé de ses éléments étrangers culturellement inadaptés :

« Est-il culturel et donc d'une certaine manière audible et respectable de recruter de très jeunes filles isolées et extrêmement pauvres, de les acheter en les terrorisant avec le rite juju, de les vendre comme le faisaient les esclavagistes, et de les exploiter en les prostituant dans des conditions sordides ? Est-il culturel et donc audible et responsable d'isoler par la langue, par l'absence de papiers à leurs noms, dans le but d'exploiter dans la

\footnotetext{
${ }^{115}$ Voir aussi Sayad A., op. cit.
} 
violence, ces enfants, parce qu'elles sont des enfants, seules, coupées de leur pays, de leur langue, de leur culture, et aussi oui de leur famille qui c'est vrai cependant les aura souvent vendues à leur proxénète ; il y a ainsi des arguments irrecevables et inaudibles car violant les principes fondamentaux des lois de la République. [...] Ces comportements délinquants portent gravement atteinte aux valeurs de la République et de la démocratie. Il est important de signifier par cette peine qu'il est impossible de vivre pour vous en France, pays où vous n'avez pas votre place pour les raisons que j'ai expliquées ${ }^{116}{ }^{\prime}$.

C'est donc par le truchement de la " culture » et du rôle particulier qu'elle jouerait dans le déploiement de formes d'infractions mettant en jeu la sexualité, que s'opèrent, dans les procès pour traite et/ou proxénétisme, la réaffirmation d'assignations racialisantes visant, entre autres, à rappeler les frontières de l'ordre national et à en délimiter les " marges sexuées et sexuelles ${ }^{117}$ ». Si « les propos qui utilisent le vocabulaire de la culture [...] assignent racialement ${ }^{118} »$, alors le culturalisme des acteurs du droit peut être lu comme une forme d'euphémisation d'autres rapports de domination ${ }^{119}$, de race mais aussi de genre, dont il rejoue les fonctions essentialisante et infériorisante tout en apparaissant comme empiriquement plus informé et socialement plus acceptable.

En France, la conception dominante du système républicain comme « aveugle aux différences » a largement contribué au silence de la littérature académique et des acteurs du droit quant à la place de la culture à l'audience, souvent présentée comme marginale ${ }^{120}$. Dans les procès pour traite et/ou proxénétisme, les justiciables et les victimes

\footnotetext{
${ }^{116}$ Observation, Anne Larcher, Présidente de chambre, Procès Afamefuna, Mai 2018, par Mathilde Darley.

${ }^{117}$ Plumauzille C., Prostitution et révolution. Les femmes publiques dans la cité républicaine (1789-1804), Clamecy, Champ Vallon, 2016, p. 14.

${ }^{118}$ Mazouz S., op. cit., p. 52.

${ }^{119}$ Belkacem L., Chauvel S., « Comment traiter de la question du culturalisme dans l'encadrement de la jeunesse ? », Agora débats/jeunesse, vol. 1, n84, 2020, pp. 41-51. Sur les usages racistes du culturalisme, voir aussi par exemple de Rudder V., Vourc'h F., « Les discriminations racistes dans le monde du travail », in Fassin D., Fassin E. (dir.), De la question sociale à la question raciale? Représenter la société française, Paris, La Découverte, 2006, pp. 175-194.

${ }^{120}$ Wyvekens A., op. cit.
} 
font pourtant l'objet de renvois réguliers à leur supposée culture, reposant sur un double mouvement de généralisation et de singularisation : d'une part, la pensée des professionnels du droit par groupes culturels présumés ( « nigérians », « chinois » ou « roms ») les constitue en «generalized others ${ }^{121} »$; d'autre part, ils et elles incarnent aux yeux de ces mêmes professionnels d' « emblématiques figures de singularité ${ }^{122} »$, en raison notamment de l'activité prostitutionnelle au fondement de leur comparution, et des particularismes culturels qu'on lui associe. Se déploie ainsi, en entretiens comme à l'audience, un cadrage culturaliste de l'infraction dont les ressorts et les effets dépassent le seul travail de description et d'ordonnancement des dossiers et des populations impliquées. Confortée par la dialectique du procès, qui voient magistrats et avocats se répondre, cette " pragmatique ${ }^{123}$ " culturaliste permet ainsi à d'autres formes d'assignations de se déployer de manière moins visible : les contours de l'ordre que les professionnels du droit ont pour mission de rétablir apparaissent alors largement dessinés par les représentations genrées et sexualisées associées aux figures de l'étranger, et auxquelles l'activité prostitutionnelle semble offrir une prise particulière. Les infractions de traite et/ou de proxénétisme visées ici permettent ainsi aux professionnels qui en jugent de rappeler non seulement le caractère hégémonique de la " culture » dont ils se font les représentants, mais également la centralité de la sexualité dans la supériorité morale et culturelle de l'ordre républicain qu'ils entendent incarner ${ }^{124}$. La « déviance » se trouve dès lors majoritairement thématisée, dans l'arène du tribunal, en lien avec son altérité profonde par rapport à l'idéaltype de sexualité « blanche ${ }^{125}$ », ni vénale ni contrainte, inscrite dans un cadre hétérosexuel conjugal et familial, et à l'aune duquel les « bonnes mœurs » se trouvent définies ${ }^{126}$. Euphémisation de la « race », avec

\footnotetext{
${ }^{121}$ Massari M., " The other and her body: Migrant prostitution, gender relations and ethnicity », Cahiers de l'Urmis, ${ }^{\circ} 12,2009$.

${ }^{122}$ Giordano C., Migrants in Translation Caring and the Logics of Difference in Contemporary Italy, Berkeley, University of California Press, 2014. Voir aussi Jacobsen C. M., Skilbrei M.-L., " 'Reproachable victims'? Representations and self-representations of Russian women involved in transnational prostitution », Ethnos, vol. 75, n², 2010, pp. 190-212.

${ }^{123}$ Didier Fassin utilise quant à lui le terme de " pragmatique ethnoraciale » : Fassin D., La force de l'ordre. Une anthropologie de la police des quartiers, Seuil, 2015 [2011], pp. 250-252.

${ }^{124}$ Stoler A.L., La Chair de l'empire. Savoirs intimes et pouvoirs raciaux en régime colonial, Paris, La Découverte, 2013.

${ }^{125}$ Dorlin E., « Les Blanchisseuses : La société plantocratique antillaise, laboratoire de la féminité moderne », in Rouch H., Dorlin E., Fougeyrollas-Schwebel D. (dir.), Le corps, entre sexe et genre, Paris, L'Harmattan, 2005 p. 145.

${ }^{126}$ Bernstein E., op. cit.
} 
laquelle elle partage le fait de penser des groupes comme homogènes à partir de l'origine des individus censés les composer, l'invocation récurrente de la «culture » dans les procès pour exploitation sexuelle invite alors à penser plus avant la « transmutation » de la question prostitutionnelle décrite par Lilian Mathieu, non plus seulement d'une " question sociale [...] en une question pénale ${ }^{127}$ », mais aussi, et surtout, d'une question pénale en une question raciale.

${ }^{127}$ Transmutation dont Lilian Mathieu rappelle qu'elle est « structurée par l'opposition entre victimes et coupables, compassion et sanction, hétéronomie et action ». Voir Mathieu L., La fin du tapin, op. cit., p. 254. 